\title{
A Study on Pragmatic Information in Chinese-English Dictionaries
}

\author{
Lixin $\mathrm{Xia}^{1}$ and Yun $\mathrm{Xia}^{2, *}$ \\ ${ }^{1}$ Laboratory of Language Engineering and Computing of Guangdong University of Foreign Studies, Guangzhou \\ 510420, China \\ ${ }^{2}$ Center for Linguistics and Applied Linguistics of Guangdong University of Foreign Studies, Guangzhou 510420, \\ China \\ *Corresponding author. Email: 1423565239@qq.com
}

\begin{abstract}
The study aims to investigate the pragmatic information in Chinese-English dictionaries. A general survey was made to examine the status quo of the pragmatic information in the existing Chinese-English dictionaries. It was found that all large- and medium-sized dictionaries under investigation provided some pragmatic information. They generally used a label to mark the style, register and subject field of the lemma and a note to show its culture and usage. The most widely used labels were subject field labels. Except a pocket dictionary, all the other eight dictionaries employed them. Then style labels were used. However, these dictionaries only provided the pragmatic information about the Chinese headword but not the English equivalent. The author argues that since the target users of these dictionaries are Chinese EFL learners, they should state clearly the pragmatic differences between the headword in the source language and the equivalent in the target language. Moreover, the cultural notes provided should be focused on the English equivalents instead.
\end{abstract}

Keywords: Chinese-English dictionary, Pragmatic information, Pragmatics, Bilingual dictionary, Lexicography, English learning and teaching.

\section{INTRODUCTION}

Pragmatic information is one of the four information categories in a general language dictionary [1, 2]. In an English learner's dictionary, pragmatic information is given through various ways [3]. For examples, in the form of short essays in the macro-structure, learners are reminded of the importance of the information about the use of words and expressions. The pragmatic and cultural information of the headword is presented implicitly or explicitly in various parts of the microstructure of the dictionary. The pragmatic information located in the micro-structure and macro-structure of the dictionary is further linked by cross-references to form a network.

Many non-linguistic factors are involved in the use of words and expressions. To understand and master these factors is the key to use them appropriately in specific situations. In cross-cultural communication, communicative barriers may arise due to pragmatic errors. Sometimes, a pragmatic error made by a foreign language learner in communication is even worse than a grammatical error. Since the middle of last century, second language teaching has attached great importance to the cultivation of learners' communicative competence.

The Chinese-English dictionary has a long history dating back to the 19th century. A great number of them were published after 1978 because of the great need to communicate with English speakers [4]. They have also begun to pay attention to pragmatic information, but there are still disputes about which pragmatic information can be presented in the Chinese-English dictionary. To a large extent, a bilingual dictionary aiming at providing the lexical unit in the source language with equivalents in the target language may fail to note the pragmatic information properly.

However, previous studies have paid little attention to pragmatic information in these Chinese-English dictionaries. In other words, what pragmatic information is provided in them and how it is presented remains to be unexplored. Therefore, this paper will investigate the pragmatic information in existing Chinese-English 
Table 1. A list of the dictionaries under investigation

\begin{tabular}{|c|c|c|}
\hline Editor and Year & Dictionary Title & Publisher \\
\hline Wu Jingrong (1978) & $\begin{array}{l}\text { A Chinese-English Dictionary (First } \\
\text { Edition) (CED1) }\end{array}$ & The Commercial Press \\
\hline Wei Dongya (1995) & $\begin{array}{l}\text { A Chinese-English Dictionary (Revised } \\
\text { Edition) (CED2) }\end{array}$ & $\begin{array}{l}\text { Foreign Language Teaching and } \\
\text { Research Press }\end{array}$ \\
\hline Yao Xiaoping (2010) & $\begin{array}{l}\text { A Chinese-English Dictionary (Third } \\
\text { Edition) (CED3) }\end{array}$ & $\begin{array}{l}\text { Foreign Language Teaching and } \\
\text { Research Press }\end{array}$ \\
\hline Wu Guanghua (2010) & The Chinese-English Dictionary (CED) & $\begin{array}{l}\text { Shanghai Jiao Tong University } \\
\text { Press }\end{array}$ \\
\hline Feng Juehua (2004) & $\begin{array}{l}\text { The Chinese-English and English- } \\
\text { Chinese Dictionary (CEECD) }\end{array}$ & Jilin University Press \\
\hline Chen Hongan (1990) & $\begin{array}{l}\text { A Pocket Modern Chinese-English } \\
\text { Dictionary (PMCED) }\end{array}$ & Xiandai Press \\
\hline Wu Wenzhi (2001) & $\begin{array}{l}\text { A Practical Chinese-English Dictionary } \\
\text { for Translation (PCEDT) }\end{array}$ & Lijiang Publishing House \\
\hline Wu Jingrong (2000) & $\begin{array}{l}\text { A New Age Chinese-English Dictionary } \\
\text { (NACED) }\end{array}$ & The Commercial Press \\
\hline Hui Yu (2003) & $\begin{array}{l}\text { A New Century Chinese-English } \\
\text { Dictionary (NCCED) }\end{array}$ & $\begin{array}{l}\text { Foreign Language Teaching and } \\
\text { Research Press }\end{array}$ \\
\hline
\end{tabular}

dictionaries with a focus on the explicit pragmatic information that is expressed clearly by a style label, a register label, a subject field label, a cultural note or a usage note. However, the implicit pragmatic information embodied in the definitions or illustrative examples will not be included in the study.

\section{DICTIONARIES SELECTED FOR THE STUDY}

In order to fulfil the objectives of the study, nine Chinese-English were selected for the study, as listed in Table 1 [5]. They were chosen because they were all published after 1978 when China adopted the reform and opening-up policy, and had a wide range of users. And they include large, medium and small-sized dictionary. New theories and findings were applied in the making of the dictionaries $[6,7,8,9]$. So they can be regarded as the representatives of the thirdgeneration Chinese-English dictionaries made in China $[10,11]$.

\section{STATUS QUO OF PRAGMATIC INFORMATION PRESENTED IN THE SELECTED DICTIONARIES}

Among the nine Chinese English dictionaries surveyed, except for the pocket Chinese English dictionary (PMCED), the other eight dictionaries provide certain pragmatic information (see Table 2), which indicates that the existing Chinese English dictionaries realize the importance of showing pragmatic information. They mainly provide pragmatic information through labels and annotations.
In Table 2, the number of style, register or subject field labels are given according to the data listed in the front matter or back matter in these dictionaries. The cultural notes and usage notes are shown by the symbol of “+” meaning available and of “-” meaning nonavailable.

The marking system uses style, register and subject field labels to show the pragmatic information. These labels are either in the form of English abbreviations as in CED2 [12], or Chinese abbreviations as in the other eight dictionaries.

Ex. 1 穿山甲... (1) zool. Pangolin (2) Chin. med. pangolin scales -- cited from CED2

Ex. 2 传檄...<古> send out a war proclamation (to expose the evil done by the enemy) -- cited from CED3

Among the nine dictionaries listed in Table 2, CED3 [9] uses 27 style labels, involving the following three main types: 1) reflecting the speaker's specific attitude, emotion and evaluation: commendatory, derogatory, sarcastic, humorous, nickname, self-depreciatory expressions, honorifics, euphemism, taboo, etc.; 2) reflecting the specific occasions where words are applicable: spoken, written, slang, idioms, fixed expressions, phraseology, formulae, etc.; 3) indicating specific semantic types: literal meaning, figurative meaning, transferred meaning, transliteration, etc.. The other eight dictionaries use fewer style labels than CED3.

CED [13] uses more subject field labels than the other eight dictionaries. Since this dictionary claims to be a comprehensive Chinese-English dictionary, it involves many disciplines. Therefore, more subject field 
Table 2. Pragmatic information in the nine dictionaries

\begin{tabular}{|l|l|l|l|l|l|}
\hline $\begin{array}{c}\text { Dictionary } \\
\text { Title }\end{array}$ & Style label & Register label & $\begin{array}{c}\text { Subject field } \\
\text { label }\end{array}$ & Cultural note & Usage note \\
\hline CED1 & 11 & 2 & 57 & + & + \\
\hline CED2 & 12 & 2 & 44 & + & + \\
\hline CED3 & 27 & 4 & 90 & + & + \\
\hline CED & 16 & 4 & 111 & + & + \\
\hline CEECD & 15 & 4 & 97 & + & + \\
\hline PMCED & - & - & - & - & - \\
\hline PCEDT & 11 & 2 & 33 & + & + \\
\hline NACED & 15 & 3 & 83 & + & + \\
\hline NCCED & 15 & 3 & + & + & + \\
\hline
\end{tabular}

labels are needed in the dictionary. However, the other dictionaries also use a certain number of subject field labels. In a word, the subject field labels are widely used in Chinese-English dictionaries in order to indicate the subject field in which the headword is used.

The marking of register in the dictionaries under investigation tends to be the same except the pocket PMCED [14]. They utilize the label "dialect" to indicate the regional use, the labels "archaic", "old use" or "classical Chinese" to indicate the currency and the label "rare use" to indicate the frequency of use.

In addition, all the dictionaries except PMCED provide some cultural notes in order to give the cultural information about culture-bound words [15, 16, 17, 18, 19]. The existing Chinese-English dictionaries include many headwords about Chinese culture. The greatest task for a dictionary-maker is to find an equivalent in the target language [20, 21]. However, they often have partial or zero equivalents in English. Therefore, encyclopaedic knowledge of the words is given to help to explain the meaning of the words. Below are some examples.

Ex. 3 五四运动...【史】 May 4th Movement of 1919 (an anti-imperialist, anti-feudal, political, and cultural movement influenced by the Russian October Revolution, led by intellectuals with some knowledge of Communist ideology) -- cited from cited from CED3

Ex. 4 黄粱美梦...〈成〉 Golden Millet Dream (from the story of a poor scholar who dreamt he had become an official but awoke to find the pot of millet still cooking on the fire)-pipe dream -- cited from cited from CED3

However, these dictionaries have some deficiencies in treating pragmatic information. First, the pragmatic information about the Chinese headwords but not the English equivalents is given. In many cases, the Chinese headwords are marked, but their English equivalents are unmarked. This may cause a misconception that they are fully equivalent.
Ex. 5 常时 chángshí 副 1 < $<$ 旧 >often; frequently; regularly (2)<方 $>$ sometimes -- cited from CED3

In Ex. 5, the register label "旧" means that the Chinese headword "常时" is an archaic word and "方" means it is a dialect; but its English equivalents are unmarked. They are neither archaic nor a dialect. The dictionary does not tell its users the difference between the Chinese headword and its English equivalents in the register uses. In this way, dictionary users may think that they are completely equivalent, which may lead to misuse.

In other cases, the Chinese headwords are unmarked words and their English equivalents are marked ones as in Ex. 6 and Ex. 7.

Ex. 6 拥抱...动 embrace; hug; hold in one's arms: -cited from CED3

Ex. 7 【电梯】 ... 名〉 lift; elevator; escalator; moving staircase: ... cited from NCCED

In Ex. 6, the Chinese headword is an unmarked common word, but its equivalent "embrace" is marked as "formal" in Oxford dictionary. In Ex. 7, the Chinese headword is an unmarked common word, but its equivalents are different in register. "lift" is a British use and "elevator" is an American one. Therefore, the dictionary users are not reminded of the stylistic and register differences between the Chinese headwords and their English equivalents, and may use them inappropriately. These problems arise from lacking full equivalence between the source language and the target language $[22,23]$.

Furthermore, the pragmatic marking in these dictionaries under investigation is not systematic. It is found that the existing Chinese-English dictionaries have not provided enough pragmatic information. And the labels were used in an unsystematic way. For example, there was a "derog." label in CED2, but there was no "approv." label. 
Finally, the existing Chinese-English dictionaries employed different pragmatic markings. Due to the lack of systematic theoretical research and support, pragmatic marking in Chinese-English dictionaries is confusing. Different labels were used for the same type of pragmatic marking in the same dictionary.

Ex. 8 传票...(1) leg. (court) summons; subpoena: 发 出 $\sim$ issue a summons (2) accounting voucher --cited from CED2

Ex. 9 多误 ... formal error; mishap --cited from CED2

Ex. 10 串门子...inf. call at sb's home; drop in:... --cited from CED2

In Ex. 8, the subject field label for sense 1 is leg., and the subject field label for sense 2 is accounting. The former one is an abbreviation, and the latter one is in its full form. In Ex. 9, the style label is formal which is in its full form. In Ex. 10, the style label is inf. which is in a shortened form. In the same dictionary, the labels should be in a uniformed form. That is to say, if the dictionary employs an abbreviation for the subject field label, all the subject field labels should be in an abbreviated form.

\section{CONCLUSIONS}

Based on the above analysis, we may conclude that existing Chinese-English dictionaries have provided some pragmatic information, but they still need improving. Firstly, the pragmatic information in Chinese-English dictionaries should include all the nonsemantic and non-grammatical constraints of the Chinese headwords and the English equivalents, including linguistic factors and external linguistic factors. Since the main target users of Chinese-English dictionaries are EFL learners and Chinese is their mother tongue, it can be assumed that they have mastered the pragmatic meaning of Chinese words. Therefore, the Chinese-English dictionary should mainly reflect the pragmatic differences between the source language and the target language, focusing on presenting the pragmatic meaning of English equivalents.

The entry of Ex. 5 can be written as below:

常 时 chángshí<副 > (1) $<$ 旧 >old use of “often; frequently; regularly” (2) $<$ 方 $>$ dialect of “sometimes”

In the above entry, we put "<旧 $>$ " and "<方 $>$ " after the sense number and before the equivalents, which means that the first sense of the Chinese headword is archaic, and the second sense of the headword is a dialect. Because they are marked before the English equivalents, they mean that the English equivalents do not have such pragmatic meanings. If the English equivalent has a pragmatic label, it should be placed after the equivalent in the entry. In this entry, due to the lack of corresponding expressions in English, we use the explanatory words of "old use of" and "dialect of" before the target language to tell the users that there are pragmatic differences between English equivalents and Chinese headwords. By this way, we can reproduce the context in dictionaries and help learners distinguish the pragmatic differences between them.

Specifically, various means can be devised to present pragmatic information in Chinese-English dictionaries in order to reproduce the contexts or situations in which the words are used, such as labels, glosses, special columns, warnings, etc.

Finally, in treating cultural information, ChineseEnglish dictionaries should focus on the cultural information of English equivalents instead of explaining only the cultural meaning of Chinese headwords. Moreover, when the cultural meanings of Chinese headwords are different from or even contradict with those of their English equivalents, Chinese-English dictionaries need to explain clearly the differences between them.

\section{AUTHORS’ CONTRIBUTIONS}

Lixin Xia conceived and designed the study and Yun $\mathrm{Xia}$, the corresponding author, wrote the paper.

\section{ACKNOWLEDGMENTS}

This work was supported by the Laboratory of Language Engineering and Computing of Guangdong University of Foreign Studies under Grant No. LEC2017ZBKT002 and the Department of Education of Guangdong Province under grant reference 2017WTSCX32.

\section{REFERENCES}

[1] B. Svensén, A Handbook of Lexicography: The Theory and Practice of Dictionary-Making, Cambridge: Cambridge University Press, 2009

[2] Y. Zhang, Contemporary Lexicography, Beijing: The Commercial Press, 2007

[3] B. T. S. Atkins, M. Rundell, The Oxford Guide to Practical Lexicography, Oxford: Oxford University Press, 2008

[4] L. Xia, A Study of a Multi-Dimensional Definition Model of the Chinese-English Dictionary for Chinese EFL Learners, Beijing: The Commercial Press, 2015. 
[5] L. Xia, A Study of the Third-Generation ChineseEnglish Dictionaries, Kernerman Dictionary News, 20 (1) (2012) 21-25

[6] A. Adamska-Sałaciak, Lexicography and Theory: Clearing the Ground, International Journal of Lexicography 32(1) (2019) 1-19

[7] G. Iamartino, Recent Bilingual English-Italian Lexicography: Insights into Usage. Dictionaries: Journal of the Dictionary Society of North America, 40(2) (2019) 133-154

[8] J. Wu, A New Age Chinese-English Dictionary, Beijing: The Commercial Press, 2000

[9] X. Yao, A Chinese-English Dictionary (Third Edition), Beijing: Foreign Language Teaching and Research Press, 2010

[10] X. Su, 2004. New Concepts of Making the FourthGeneration Chinese-English Dictionaries: A Review of A New Century Chinese-English Dictionary. Foreign Language Teaching and Learning, 3 (2004) 6-8

[11] L. Xia, Some Reflections on the Making of Chinese-English Dictionaries, Publishing Science, 2 (2011) 23-27

[12] D, Wei, A Chinese-English Dictionary (Revised Edition), Beijing: Foreign Language Teaching and Research Press, 1995

[13] G. Wu, The Chinese-English Dictionary, Shanghai: Shanghai Jiao Tong University Press, 2010
[14] H. Chen, A Pocket Modern Chinese-English Dictionary, Beijing: Xiandai Press, 1990

[15] J. Wu, A Chinese-English Dictionary (First Edition), Beijing: The Commercial Press, 1978

[16] J. Feng, The Chinese-English and EnglishChinese Dictionary, Changchun: Jilin University Press, 2004

[17] W. Wu, A Practical Chinese-English Dictionary for Translation, Guilin: Lijiang Publishing House, 2001

[18] J. Wu, A New Age Chinese-English Dictionary, Beijing: The Commercial Press, 2000

[19] Y. Hui, A New Century Chinese-English Dictionary, Beijing: Foreign Language Teaching and Research Press, 2003

[20] A. Adamska-Sałaciak, Examining Equivalence, International Journal of Lexicography, 23(4) (2010) 387-409

[21] Zgusta, L. 1971. Manuel of Lexicography. The Hague Paris: Mouton.

[22] A. Adamska-Sałaciak, Issues in compiling bilingual dictionaries, in: H. Jackson (Eds.), The Bloomsbury Companion to Lexicography, London: Bloomsbury Academic, 2013, pp. 213-231

[23] A. Heijns, 2020. In Pursuit of Genuine Chinese Equivalents: The Case of a Nineteenth-Century Dutch-Chinese Dictionary, International Journal of Lexicography, 33(1) (2020) 104-115 